\title{
Composite Automobile Fender Impact Testing with a Spherical Ball
}

\author{
EMILIAN-IONUT CROITORU ${ }^{1 *}$, CRISTIN-OLIMPIU MORARIU ${ }^{1}$, ADRIAN SOICA ${ }^{2}$, \\ GHEORGHE OANCEA ${ }^{1}$ \\ ${ }^{1}$ Transilvania University of Brasov, Department of Manufacturing Engineering, 5 Mihai Viteazul Str., Brasov, Romania \\ ${ }^{2}$ Transilvania University of Brasov, Department of Automotive Engineering, 29 Eroilor Blvd., Brasov, Romania
}

\begin{abstract}
The research carried out within this paper addresses the issue of impact analysis with a spherical ball of an automobile fender, following two directions: the finite element method modeling of named part and situation, and experimental validation of the study mentioned beforehand. The part itself - car fender - is represented by a thermoset composite panel armed with Kevlar-Carbon fibers, while the analyzed situation is depicted as a Charpy/Izod test with a spherical ball on the specified component. The evaluation of named inquiry is performed in a virtual environment by means of FEA and verified accordingly within laboratory testing.
\end{abstract}

Keywords: automobile fender, composite materials, impact analysis, spherical ball

\section{Introduction}

The increase in priority given by industrial companies towards composite materials development, manufacturing and utilization, towards design and enhancement of structure made out of this type of materials, towards the characterization and knowledge of the macro and micro-mechanical behavior of such structures in the assemblies they are a component of - aircrafts, automobiles, naval ships a.s.o., towards the variety of loading, towards the report between cost and quality in the fabrication of these assemblies, and, also, the concern of the authors for this interdisciplinary domain, have led to the present research [1].

The present research is in the international trend, this fact being demonstrated by the high number of papers published in the recent years in journals and specialty books and by the appearance on the commercial market of different products from composite materials. The products themselves are developed by companies which offer the technological support for the amplification of the domain's evolution and expansion [1].

The research presented hereafter enrolls in the coordinates of composite panels' calculation and analysis. Specifically, thermoset composite panels armed with Kevlar-Carbon fibers subjected to impact. The inquiry follows three directions: one mathematical approach for the calculation of certain parameters, one finite element modeling method to procure results in the form of deformations and stresses on the selected assessed part, and laboratory testing to validate the results obtained from the mentioned virtual situation. The goal of the investigation is to optimize a given structure $-\mathrm{a}$ left fender of an automobile - from its current metallic material composition to a composite material one, the fender being subjected to impact with a spherical ball. The analysis itself is depicted as a Charpy/Izod test in virtual reality and actual reality. The high numbers of external and internal factors which influence the structures' assessment have driven this research towards a systematic and rigorous approach which implies mathematical concepts and engineering know-how of various domains such as strength of materials, engineering and design of structures [1].

The research started with a state of the art section to emphasize the importance of the selected thematic, then continues with a finite element analysis section that gives details for CAD modeling, meshing of selected part, integration and setup of finite element simulation, results presentation in the

*email :emil.ca2651@yahoo.com 
form of displacements and stresses and their interpretation, with the laboratory testing performed on a manufactured fender to validate the virtual reality results, and ends with conclusions and future course of inquiry.

As mentioned beforehand, the impact analysis of plates - metallic or composites - is a domain of high interest and one which requires notions of strength of materials, engineering, design and calculation of structures and others. An area where the scientific community develops new methods of assessment as shown in multiple inquiries published worldwide.

Although the finite element method is not new [2], teams of researchers have started to analyze the impact of certain structures only recently. Furthermore, the collected data from the finite element simulations are also validated by means of experimental testing in order to corroborate the virtual reality with actual reality. For example, the issue of modeling a ballistic impact of an armor made out of composite material armed with fiberglass has been solved [3] by determining the property of named armor through quasi-static traction tests, then implementing them on a 3D model in the software LSDYNA and subjecting this representation to impact at a velocity of $560 \mathrm{~m} / \mathrm{s}$.

The finite element method has also been used to design structures made of composite material such as turbine blades. It was determined that the FE model presents deformations close to reality based on the thickness of the lamina and the accuracy of the lamina setup [4].

Continuing, one study was conducted regarding the compression properties of a 3D composite structure armed with Carbon fibers within an epoxy resin matrix for a temperature interval between $23^{\circ} \mathrm{C}-210^{\circ} \mathrm{C}$ [5]. It was concluded that the high temperature has a negative effect on the compression properties with the elasticity modulus in compression having a decrease at $120^{\circ} \mathrm{C}$, which is the transition temperature of the resin. On the same note, the effects of multiple failure criteria - such as Puck, Hashin and Chang-Chang criteria - on Carbon composite has been studied [6]. The finite element model created in the virtual environment ABAQUS and software Python is used the analysis of probes of Carbon composite panels with difference layups and impact energies. The obtained results are employed in the determination of mathematical curves between force - time - deformation and dissipated energy. This research represents a support for the selection of composite materials and their failure criteria to ensure optimum results in numerical simulations.

In the recent years, numerical models for the simulation of impact and post-impact compression calculation have been developed, especially in the aerospace field. With its 14 input parameters, the study [7] demonstrates a good correlation between model and experiment thru the impact force deformation curve, post-impact compression - deformation curve, post-impact delamination and postimpact imprints. Another paper presents a model which implies 7 parameters for the description of the meshed elements' behavior in the software ABAQUS [8]. The theoretical approach of this study is represented by the implementation of the macro mechanical coordinates of the assessed composite material. The results are also compared to the ones obtained by tests with special equipment in the laboratory.

Algorithms for the design of dynamic responses and failure mechanism of laminates containing plastic fibers and polymer matrix subjected to low velocity impact have also been researched [9]. With the help of the application ABAQUS-VUMAT, a comparison between multiple material probes has been made by impact force - time, deformation - time and dissipated energy - impact energy curves comparison.

A simplified failure model of composite plates subjected to impact has been related with the software ABAQUS [10]. The results of the simulation describe the conduct of such plates with regards to the lamina's compression. They also consider the drop in mechanical strength of the plate itself due to the interruption of arming fibers. Another response for the impact at low velocity of composite material configurations has been noted [11] by means of software LSDYNA, where the Bouligand structure with spiral form presents the best characteristics and the smallest number of deteriorated fibers. 
An investigation with dedicated software applications ABAQUS and Matlab has been performed in order to capture the influence of the delamination size, lamina sequence and boundary conditions on the vibrations behavior of composite structures [12]. Also, with ABAQUS/Explicit module, a strategy has been presented for the finite element analysis of laminates subjected to impact and their postimpact compression parameters [13].

Studies are also performed to improve the crashworthiness performance in low-velocity impact of an automobile front bumper beam by changing the material and thickness [14], [15]. Also, the shape and impact condition are studied from a design point of view to improve the front bumper beam [16]. Improvements are being made in the material domain by testing different composite materials for the same part [16].

\section{Materials and methods}

\section{Finite element analysis and experimental testing}

\section{CAD Modeling}

The selected part for analysis is a fender from an automobile (Figure 1 and

Table 1). In order to obtain the CAD model of the part, several steps are performed which include: images insertion in an orthogonal coordinate system belonging to a virtual CAD environment and their alignment by reference points identification, points and lines construction on the contour of the fender in the three planes of the coordinate system, and, finally, the surface creation of the analyzed structure. The images to be inserted at the beginning of the CAD modeling process are the front view, top view and lateral view of the selected automobile [1].

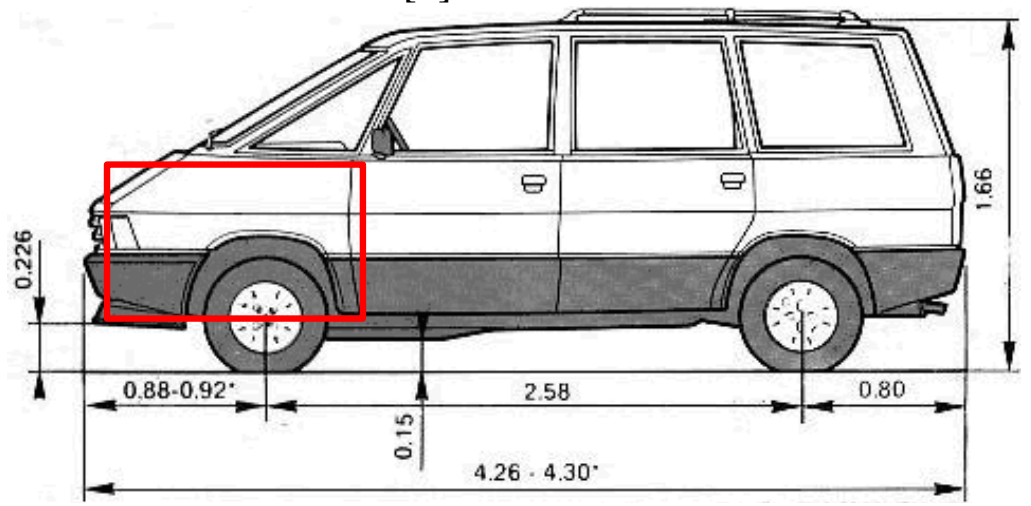

Figure 1. Specifications of the selected automobile [18]

Table 1. Geometrical details of the selected automobile [18]

\begin{tabular}{|c|c|}
\hline Technical specification & Value \\
\hline Length & $4260 \mathrm{~mm}$ \\
\hline Width & $1777 \mathrm{~mm}$ \\
\hline Height & $1660 \mathrm{~mm}$ \\
\hline Wheelbase & $2580 \mathrm{~mm}$ \\
\hline Weight & $1312 \mathrm{~kg}$ \\
\hline Maximum weight (when loaded) & $2080 \mathrm{~kg}$ \\
\hline Tire type & $195 / 65 \mathrm{R} 13$ \\
\hline Tire height & calculated hereafter with equation (1) \\
\hline
\end{tabular}

The tire height, edge height and wheel diameter, are calculated as follows:

$w_{\text {wheel }}=195 \mathrm{~mm}$

$A R=65 \%$

$h_{\text {edge }}=w_{\text {wheel }} * A R=195 \mathrm{~mm} * 0.65=126.75 \mathrm{~mm}$

$D_{\text {rim }}=13$ inch $=330 \mathrm{~mm}$

$D_{\text {wheel }}=h_{\text {edge }} * 2+D_{\text {rim }}=126.75 \mathrm{~mm} * 2+330 \mathrm{~mm}=583.5 \mathrm{~mm}$ 
where the parameters are:

- $\mathrm{w}_{\text {wheel }}$ - wheel width;

- AR - Aspect Ratio;

- $\mathrm{h}_{\text {edge }}$ - edge height;

- $\mathrm{D}_{\text {rim }}$ - rim diameter;

- $\mathrm{D}_{\text {wheel }}$ - wheel diameter.

The values shown in

Table 1 and the values computed using equation (1) are used to generate the $3 \mathrm{D}$ model of the fender shown in Figure 2.

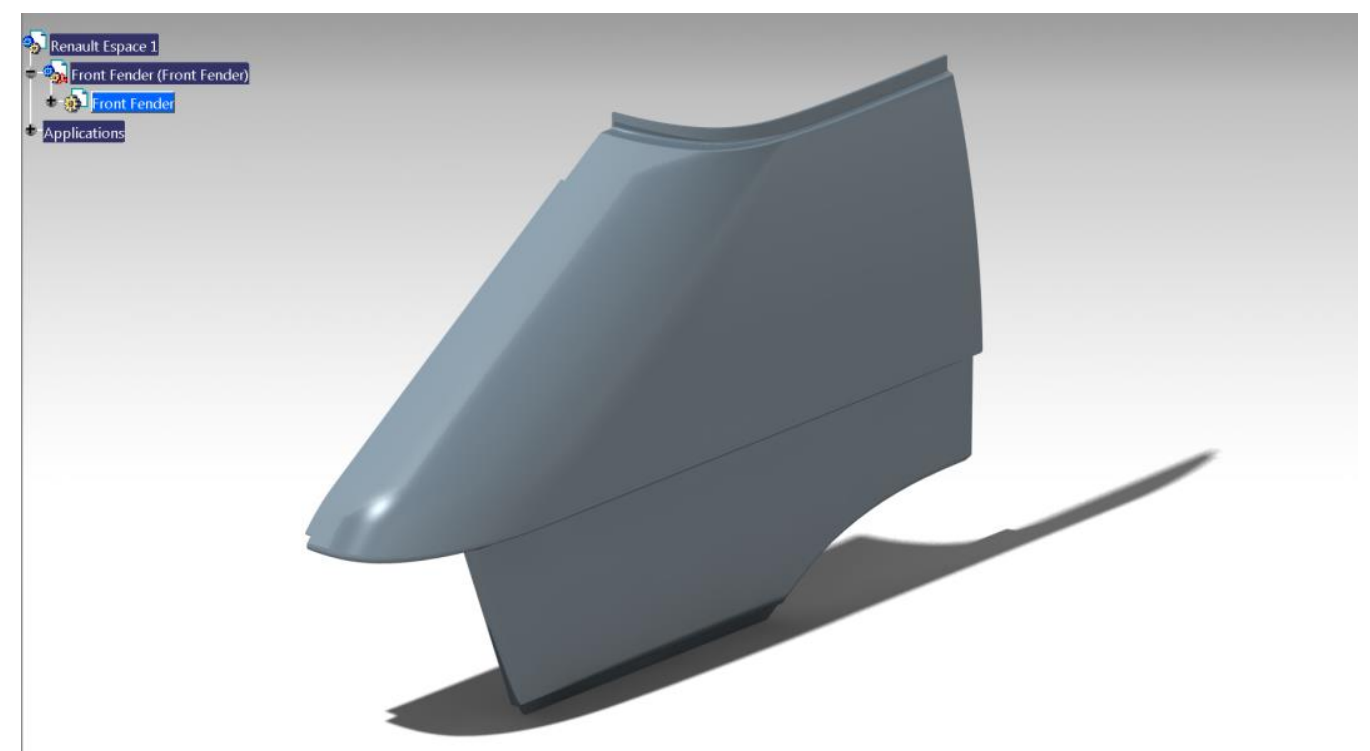

Figure 2. Fender 3D view in CATIA virtual environment [1]

\section{Meshing of CAD Model}

The meshing of the CAD model (Figure 3) is performed by following the workflow described hereafter: a) CAD model is imported in a specific application for meshing; b) geometry is cleaned-up of points, lines and surfaces considered irrelevant FEM-wise; and c) meshing of complete structure.

The size of the used elements is $5 \mathrm{~mm}$ by taking into consideration the dimensions of the fender as shown in

Table 1. Furthermore, the elements chosen for this meshing are plate elements CQUAD4 and CTRIA3 which represent a membrane subjected to bending and/or plane loads in an iso-parametric manner [1]. The plate elements are generated automatically by the software considering the geometry of the part to be meshed. 


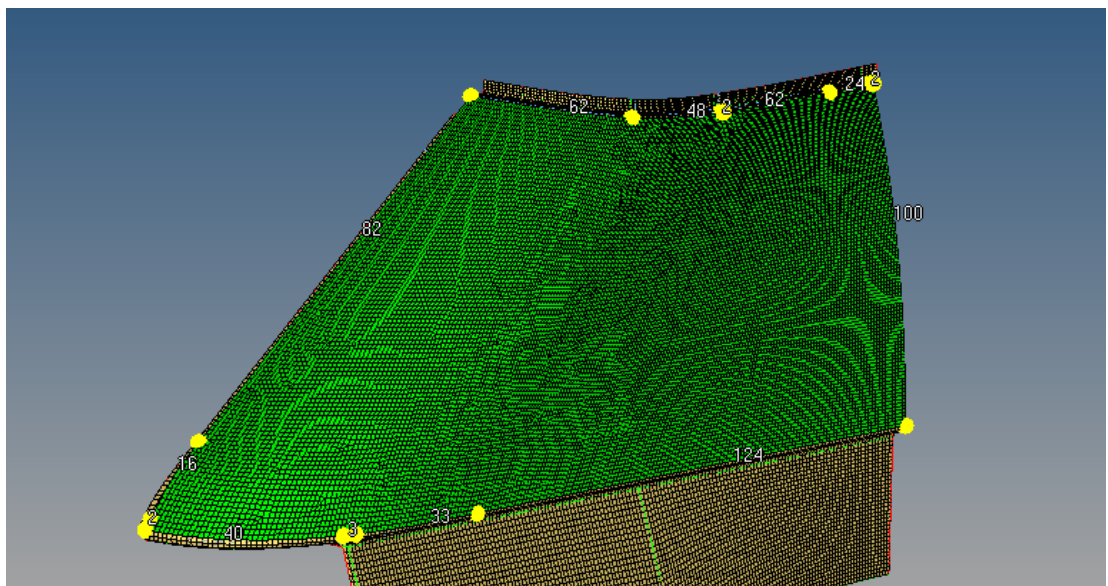

Figure 3. Fender 3D view with meshing details [1] 


\section{Finite Element Model Integration}

In order to finalize the finite element model assembly, to the automobile fender FE model, two more parts are added: the spherical impact ball and the pendulum it is attached to. Their characteristics are presented below, [1]:

- Impact ball (Figure 4):

○ $100 \mathrm{~mm}$ diameter;

० $5 \mathrm{~kg}$ mass;

o Meshing of spherical outer surface is made also with CQUAD4 plate elements of $5 \mathrm{~mm}$ in size;

o Nodes of outer surface are connected to the gravity center of the impact ball by means of a rigid body element, which is connected to the pendulum afterwards.

- Pendulum (Figure 5):

$\circ 1100$ mm length;

○ $22 \mathrm{~mm}$ by $22 \mathrm{~mm}$ transversal section with a $5 \mathrm{~mm}$ wall thickness by considering CBAR section elements;

o One side is connected to the impact ball while the other presents the single point constraints required for the FE modeling.

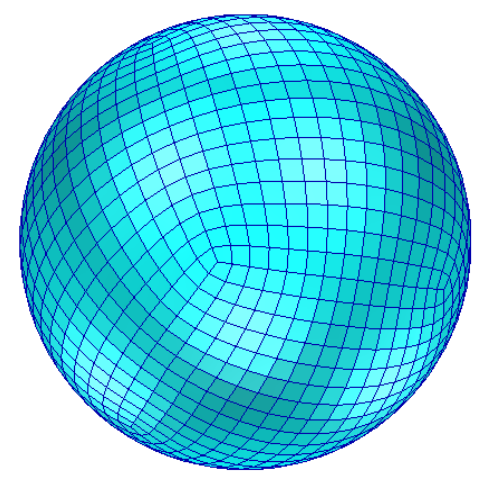

Figure 4. Impact ball meshing detail [1]
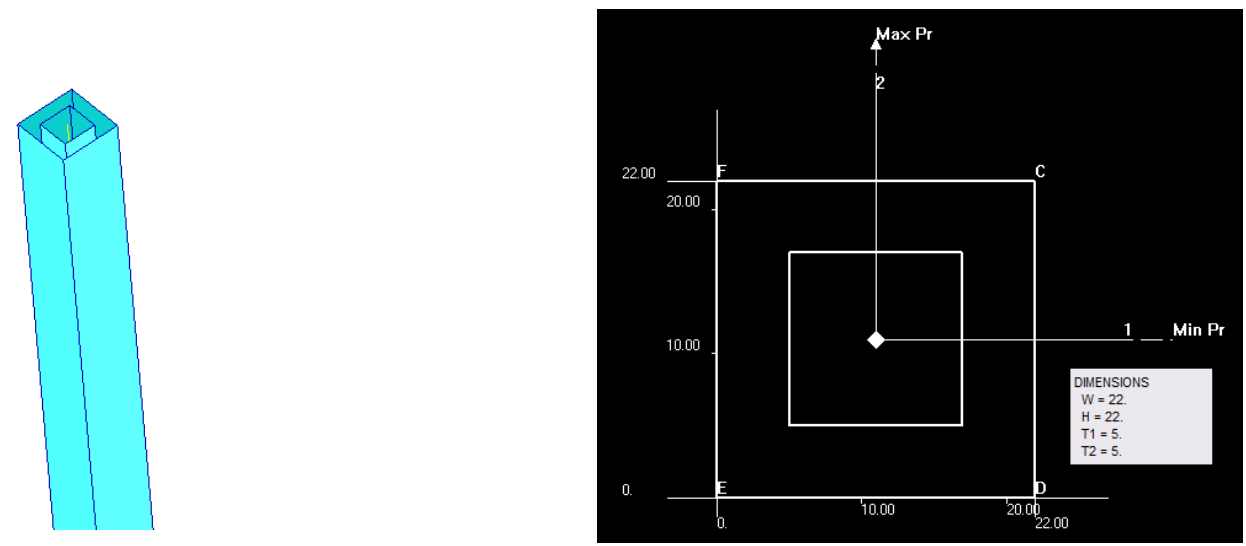

Figure 5. Geometry of the pendulum cross-section [1]

\section{Criteria for Finite Element Model}

For a rigorous FE analysis to lead to results comparable to laboratory tests and, also, in order to cover a large variety of simulations, combinations after the following criteria are performed, [1]:

- Material criteria - the elements of the finite element model assembly obtained previously will have the material characteristics shown in Table 2; three types of materials are considered for the fender - steel, aluminum and composite. 
- Energy criteria - the kinetic energy at the moment of impact is equal to the potential energy of the ball and, implicitly, of the pendulum swing angle measured from the vertical position which represents the stabile equilibrium position of the assembly; the speed factor inside the kinetic energy term becomes directly proportional with the factors for gravitational acceleration and height from the potential energy term.

Equation (2) is used to compute the velocity of the impact ball:

$$
\begin{aligned}
& E_{c}=E_{p} \\
& E_{c}=\frac{m * v^{2}}{2} \\
& E_{p}=m^{*} g * h \\
& h=r-r * \cos \alpha
\end{aligned} \mid \Rightarrow \frac{v^{2}}{2}=g * h \Rightarrow v=\sqrt{2 * g * h}=\sqrt{2 * g * r *(1-\cos \alpha)}
$$

where the parameters are: $\mathrm{g}$ - gravitational acceleration, $\mathrm{r}$ - length of pendulum, $\alpha$ - angle between starting position and vertical position of pendulum. The graphical representation of this equation is given in Figure 6.

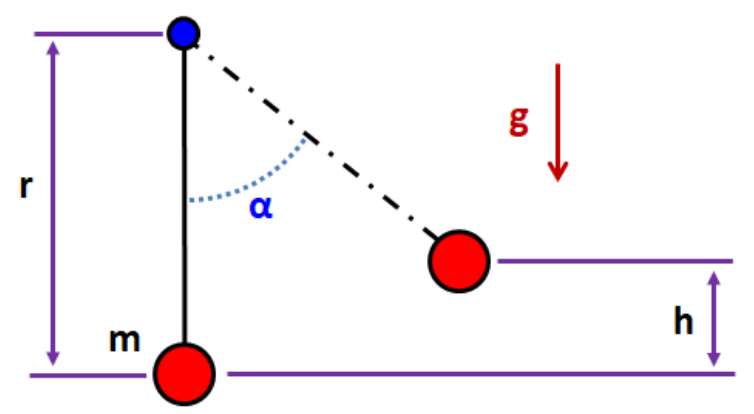

Figure 6. Graphical representation of equation (2) [1]

It is taken into consideration that the automobile fender will be simulated with three different types of materials (steel, aluminum and composite) and the pendulum and impact ball assembly initial position will have three values $\left(45^{\circ}, 90^{\circ}\right.$ and $\left.160^{\circ}\right)$. Thus, a total of 9 simulations of the finite element model described beforehand will be conducted [1]. Only the results for the composite fender are presented in this paper.

\section{Simulation Setup}

The simulation setup of the FE model assembly created beforehand is reported hereafter, [1].

First, the material is created and applied on the parts subjected to analysis - composite fender, impact ball and pendulum. The material properties are given in Table 2, while the configuration used for the composite fender - meaning 0/90/45/-45/0/0/-45/45/90/0 - is shown in Table 3. The constituents of the composite material are Carbon Fibers for layers situated at $0^{\circ}$ and $90^{\circ}$ and Kevlar Fibers for layers at $45^{\circ}$ and $-45^{\circ}$. All fibers have a thickness of $0.5 \mathrm{~mm}$ which yields a $5 \mathrm{~mm}$ thickness for the composite fender.

The next step in the simulation setup is the boundary conditions implementation on the FE model assembly as shown in Figure 7. This step is performed by considering only the connections with structural role of the parts themselves (i.e. composite fender is held at its margins by rivet holes and leans on an adaptive frame) and the rotation movement of the pendulum. Boundary conditions applied on the composite fender are "123456" and on the pendulum are "12356"; each number stands for one translation $(1$ - on X-axis, 2 - on Y-axis, 3 - on Z-axis) or one rotation (4 - about X-axis, 5 - about Yaxis, 6 - about Z-axis); the missing number " 4 " for the boundary conditions of the pendulum means that the part is allowed to rotate about the $\mathrm{X}$-axis in the shown coordinate system.

Continuing, the gravitation acceleration of value $9810 \mathrm{~mm} / \mathrm{s}^{2}$ with a negative sign with respect to the $\mathrm{Z}$-axis is added and the assignment of contacts between each of the parts is made (i.e. impact ball 
can make contact with the composite fender - pink dots displayed in Figure 7). The last step before the simulation run is the calculation of parameters setup. Close attention is given to the running time of the pendulum for two reasons: 1) a small running time might mean no impact between the ball and the fender and 2) a high running time might mean multiple contacts between the two mentioned parts. Both these situations are not desired. The required parameters for the simulation run are inserted into the pre- and post-processor software application Patran by means of command panels. The outcome of these directions is a file with the extension "bdf" which is required by the mathematical solver Nastran in order to receive results of the desired FE simulation [1].

Finally, the simulation is performed and results can be acquired and discussed.

Table 2. Material properties of all parts from FE model ([19] and [20])

\begin{tabular}{|c|c|c|c|c|c|c|c|c|c|}
\hline $\begin{array}{c}\text { Component } \\
{[-]}\end{array}$ & $\begin{array}{c}\text { Material } \\
\text { Type } \\
{[-]}\end{array}$ & \multicolumn{3}{|c|}{$\begin{array}{l}\text { Longitudinal } \\
\text { Young's } \\
\text { Modulus } \\
{[\mathrm{MPa}]}\end{array}$} & $\begin{array}{c}\text { Poisson's } \\
\text { Coefficient } \\
{[-]}\end{array}$ & \multicolumn{3}{|c|}{$\begin{array}{l}\text { Transversal } \\
\text { Young's } \\
\text { Modulus } \\
\text { [MPa] } \\
\end{array}$} & $\begin{array}{l}\text { Density } \\
{\left[\mathrm{kg} / \mathrm{m}^{3}\right]}\end{array}$ \\
\hline $\begin{array}{c}\text { Fender I } \\
\text { Impact Ball } \\
\text { Pendulum }\end{array}$ & Steel & \multicolumn{3}{|c|}{210000} & 0.30 & \multicolumn{3}{|c|}{81000} & 8100 \\
\hline Fender II & Aluminum & \multicolumn{3}{|c|}{71000} & 0.33 & \multicolumn{3}{|c|}{26700} & 2800 \\
\hline \multirow{3}{*}{ Fender III } & Fiberglass & 20000 & 20000 & 20000 & 0.20 & 3000 & 1 & 1 & 3000 \\
\hline & Carbon Fiber & 56000 & 56000 & 56000 & 0.18 & 2850 & 1 & 1 & 2850 \\
\hline & Kevlar Fiber & 25900 & 25900 & 25900 & 0.70 & 1 & 60 & 30 & 37 \\
\hline
\end{tabular}

It can be observed that no epoxy matrix material properties are presented. This aspect is a consequence of the fact that the software used for this analysis considers a perfect bonding between the Carbon Fiber and Kevlar Fiber. Thus, the epoxy resin between the fibers is not simulated.
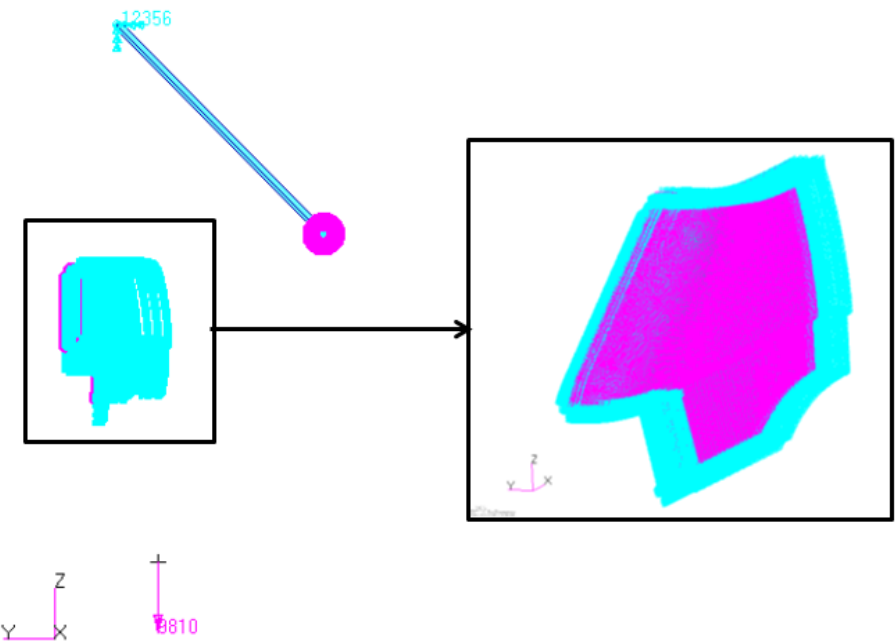

Figure 7. FE model ready for simulation run [1]

Table 3. Composite property presentation [1]

\begin{tabular}{|c|c|c|c|}
\hline $\begin{array}{c}\text { No. } \\
{[-]}\end{array}$ & $\begin{array}{c}\text { Material Name } \\
{[-]}\end{array}$ & $\begin{array}{c}\text { Thickness } \\
{[\mathrm{mm}]}\end{array}$ & $\begin{array}{c}\text { Orientation } \\
{\left[{ }^{\circ}\right]}\end{array}$ \\
\hline 1 & Carbon Fiber & 0.5 & 0 \\
\hline 2 & Carbon Fiber & 0.5 & 90 \\
\hline 3 & Kevlar Fiber & 0.5 & 45 \\
\hline 4 & Kevlar Fiber & 0.5 & -45 \\
\hline 5 & Carbon Fiber & 0.5 & 0 \\
\hline 6 & Carbon Fiber & 0.5 & 0 \\
\hline 7 & Kevlar Fiber & 0.5 & -45 \\
\hline 8 & Kevlar Fiber & 0.5 & 45 \\
\hline 9 & Carbon Fiber & 0.5 & 90 \\
\hline 10 & Carbon Fiber & 0.5 & 0 \\
\hline
\end{tabular}




\section{Manufacturing of analyzed part}

The beforehand step with regards to part manufacturing is the one referring to mold fabrication. The mold is made after an original part by following the workflow described below, [1]:

- Stiffness stencil realization after the original part is taken off the automobile; this step is necessary considering the part itself could suffer certain geometrical deviations caused by its manipulation;

- Stiffness stencil and original part dismantling;

- Water jet washing of part and its fixation on a stiffness frame;

- Application of release wax on the part; this step presumes the part is covered with 3 successive layers of wax with dry and polish after each ply is set;

- Surface layer application to ensure the interface between the part covered in wax and the fiberglass impregnated with epoxy resin;

- Tailoring of fiberglass; this step is made by covering the part with 6 layers of fiberglass having a density of $450 \mathrm{~g} / \mathrm{m}^{3}$;

- Epoxy resin preparation and impregnation into the fiberglass layers;

- Polymerization for $24 \mathrm{~h}$ according to the fiberglass and epoxy resin producer's standard;

- Removal of mold from original part;

- Mould margins cutting, finishing and polishing.

The end result for this process is shown in Error! Reference source not found.. Thus, the manufacturing process of the composite automobile fender from material Kevlar-Carbon $215 \mathrm{~g} / \mathrm{m}^{3} \mathrm{can}$ begin. The operations implied by this procedure are presented hereafter, [1]:

- Execution of part material tailoring after the geometric contour of the mold;

- Preparation and application of one layer of epoxy resin with the required dry afterwards;

- Preparation of surface resin and application of mentioned resin in multiple layers;

- Dry of result assembly;

- Polish of surface;

- Thermal treatment of part; this step presumes the insertion of complete assembly into an oven for the enhancement of mechanical characteristics by temperature increase $\left(5^{\circ} \mathrm{C} / \mathrm{h}\right)$, temperature maintain at $120^{\circ} \mathrm{C}$ for $5 \mathrm{~h}$ and gradual temperature decrease of entire assembly at room temperature.

The complex geometric part, left fender of the selected automobile, resulted from the workflow described beforehand is shown in Error! Reference source not found.

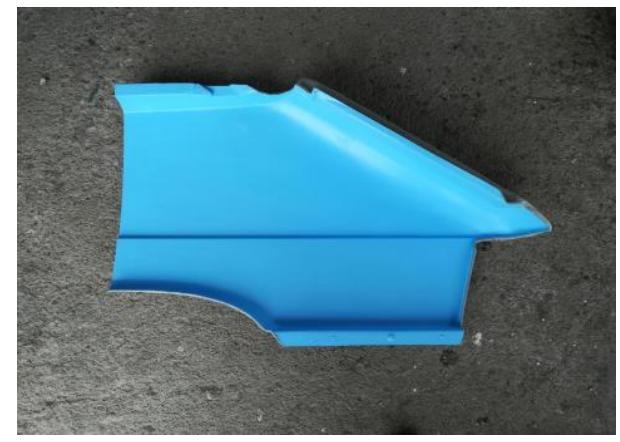

Figure 8. Mould of analyzed part [1]

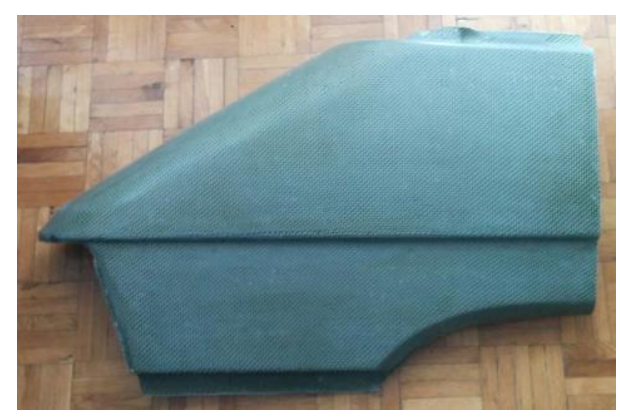

Figure 9. Analyzed

part subjected to 


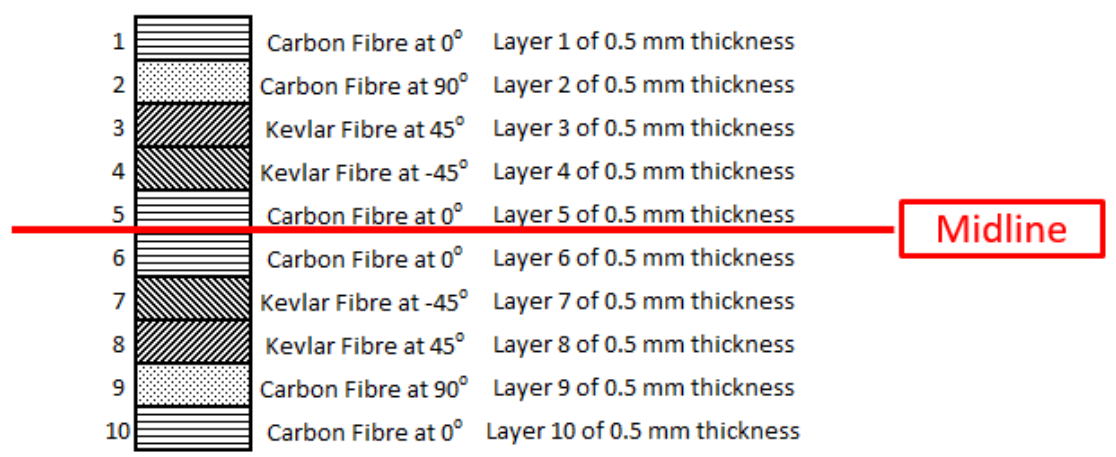

Figure 10. Cross-section of composite fender [1]

\section{Theoretical aspects of proposed experiment}

In order to investigate the behavior of the composite fender under impact, a laboratory experiment was conducted. Figure 11 shows the configuration of the proposed experiment.

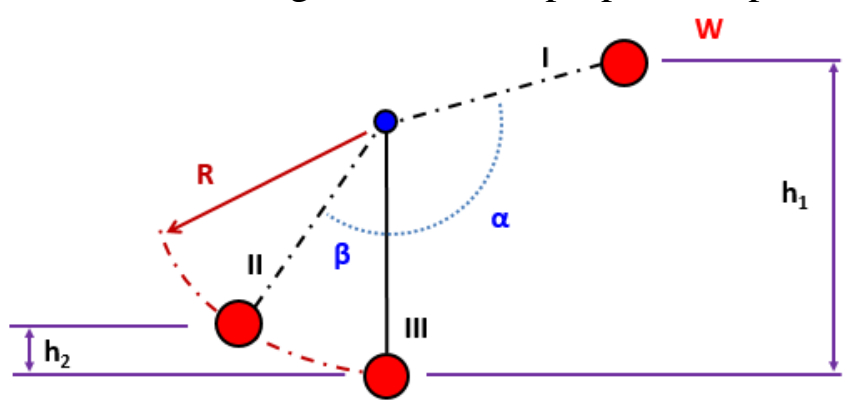

Figure 11. Graphical representation of conducted experiments [1]

Thus, the conducted analysis has the subsequent input parameters, [1]:

- Swing angle $\alpha$ (or fall angle) as the initial angle of the spherical impact ball;

- Swing angle $\beta$ (or end angle) as the final angle of mentioned ball;

- Radius of pendulum R;

- Weight of ball W;

- Energy loss L;

- Gravitational acceleration g (equal to $9810 \mathrm{~mm} / \mathrm{s}^{2}$ ).

The laboratory tests' course of action is shown hereafter, meaning the impact ball starts in position III, is brought into the initial test position I from where it is released, it journeys along the distances described by the swing angles $\alpha$ and $\beta$, it impacts the composite automobile fender and stops. One important note is that for these tests the swing angle $\beta$ and the energy loss L are considered null [1].

With regards to the second aspect, the equation for the maximum impact energy calculation is given by the following relation:

$$
\Delta U=U_{1}-U_{2}=m^{*} g * h_{1}-m^{*} g * h_{2}=m^{*} g *\left(h_{1}-h_{2}\right)
$$

where: $\mathrm{m}$ is the mass of the impact ball, $\mathrm{g}$ is the gravitational pull, $\mathrm{h}_{1}$ is the swing start height and $\mathrm{h}_{2}$ is the height at swing finish.

By replacing the heights as functions to the swing angles, is obtained the following equation:

$$
E=W^{*} g * R *(\cos \beta-\cos \alpha)-L
$$

where: $\mathrm{W}$ is the impact ball weight, $\mathrm{g}$ is the gravitational acceleration, $\mathrm{R}$ is the pendulum length, $\alpha$ is the swing fall angle, $\beta$ is the swing end angle and $L$ is the energy loss. 
Taking into consideration the note mentioned beforehand, the impact energy will be directly influenced by the swing angle $\alpha$, while the other parameters are identical. Thus, multiple tests were performed by considering the following swing angles: $45^{\circ}, 90^{\circ}$ and $160^{\circ}$, the last value being the maximum swing angle of the experimental stand. By considering the formula above, the maximum impact energy and its equivalent in acceleration for each angle is, [1]:

- $29 \mathrm{~J}$ and $2.9 \mathrm{~g}$ for a swing angle of $45^{\circ}$;

- $98 \mathrm{~J}$ and $10.1 \mathrm{~g}$ for a swing angle of $90^{\circ}$;

- $190 \mathrm{~J}$ and $19.4 \mathrm{~g}$ for a swing angle of $160^{\circ}$.

\section{Experimental Stand}

In order to perform the laboratory tests, the following experimental stand (Figure 12 and ) has been configured with the components mentioned below, [1]:

- Rigid support - the part that represents the support basis of the entire assembly, its components being rigid bars welded together with sustaining soles at their end;

- Pendulum - the element tied to the rigid support, mounted on a bearing on one end and with the spherical impact ball at the other end;

- Impact ball - the constituent which makes the actual collision and energy transfer with the analyzed fender;

- Adaptive frame - the component on which the fender is mounted;

- Automobile fender - analyzed part.

Table 4. Geometrical details

of experimental stand [1]

\begin{tabular}{|c|c|}
\hline Technical specification & Value \\
\hline Height & $3000 \mathrm{~mm}$ \\
\hline Width & $1200 \mathrm{~mm}$ \\
\hline Depth & $2000 \mathrm{~mm}$ \\
\hline Length & $2000 \mathrm{~mm}$ \\
\hline Maximum swing angle & 160 degrees \\
\hline
\end{tabular}

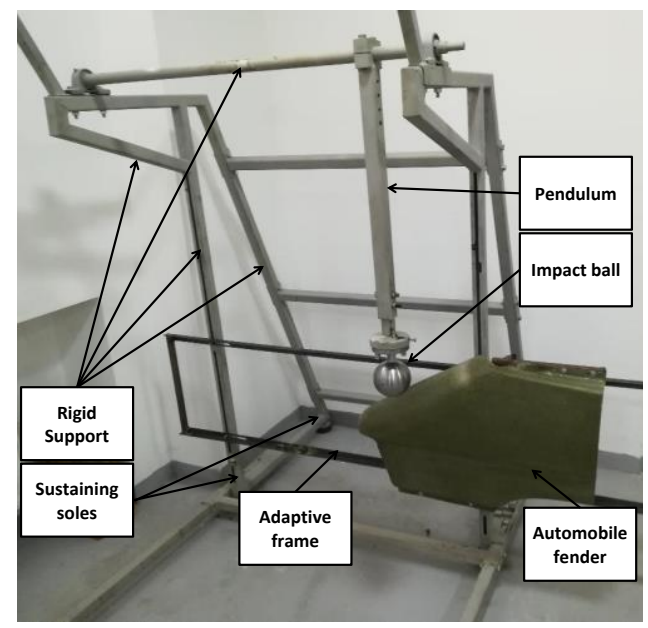

Figure 12. Experimental stand configuration [1]

On the impact ball, a hole has been made for the mounting of one accelerometer, necessary for the data recording of each test. By an electric wire, a connection is made to a piezometer for the electric impulse caption thru three canals representing the three accelerations in an orthogonal coordinate system. Also, the piezometer sends the data to a translator which makes the digital transformation of 
the input inside a software application (Figure 13). These results represent the final information which will be transposed into graphics and mathematical models [1].

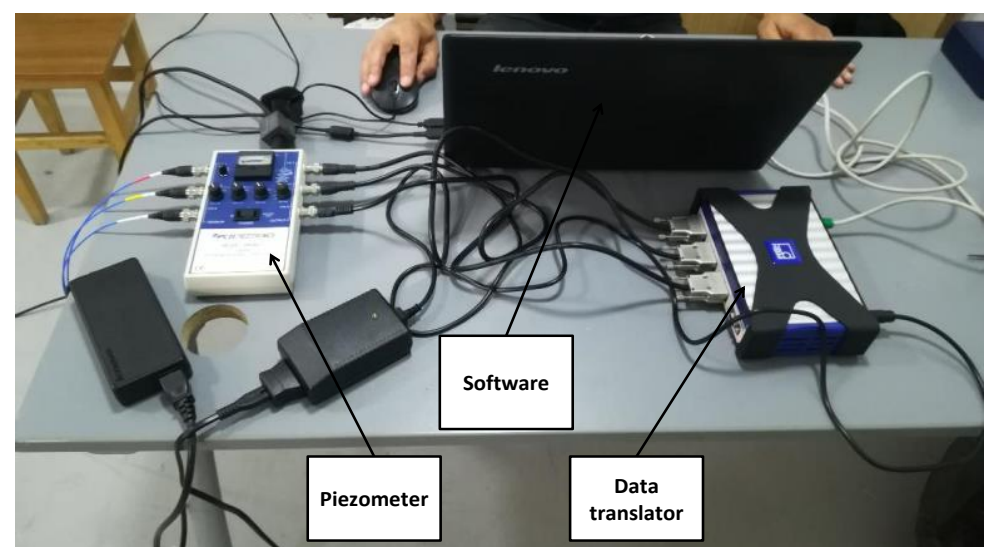

Figure 13. Experimental data acquisition and translation [1]

\section{Results and discussions}

The final act with regards to the coupled finite element analysis - experimental study performed to understand the behavior of composite fender under impact loads is the results presentation and interpretation from the simulation runs and laboratory tests performed on named fender.

First, in order to determine the correctness of the solutions resulted from the virtual environment, a comparison between the velocity computed with equation (2) and velocity obtained from FE analysis is performed in Error! Reference source not found.. The trajectory of the impact ball' center of gravity is shown in

Figure 14

Table 5. Velocity comparison table for composite fender [1]

\begin{tabular}{|c|c|c|c|}
\hline $\begin{array}{c}\text { Simulation } \\
{[-]}\end{array}$ & $\begin{array}{c}\text { Calculated } \\
\text { Velocity } \\
{[\mathrm{mm} / \mathrm{s}]}\end{array}$ & $\begin{array}{c}\text { FE simulation } \\
\text { Velocity } \\
{[\mathrm{mm} / \mathrm{s}]}\end{array}$ & $\begin{array}{c}\text { Difference } \\
{[\%]}\end{array}$ \\
\hline Simulation at $45^{\circ}$ swing angle & 2514.164 & 2192.373 & 12.80 \\
\hline Simulation at $90^{\circ}$ swing angle & 4645.582 & 4014.906 & 13.58 \\
\hline Simulation at $160^{\circ}$ swing angle & 6470.093 & 5262.532 & 18.66 \\
\hline
\end{tabular}

Although the results given in Error! Reference source not found. show a high difference between the two considered velocities, the results are considered acceptable based on the following arguments: a) equation (2) describes the velocity as a linear term directly proportional to $\mathrm{g}$ - gravitational acceleration, $\mathrm{r}$ - length of pendulum and $\alpha$ - angle between starting position and vertical position of pendulum, while the FE simulation takes into consideration the second and third order terms of the differential equations used to compute velocity; b) after each interval of 0.005 seconds during the simulation run, the velocity is recalculated considering all variables which influence it (i.e. acceleration increase or decrease generated by the gravitation pull); c) at the moment of impact, friction occurs between the parts which come together (composite fender and impact ball), thus creating a deceleration, which is considered by the FE simulation, but not by equation (2); and d) the trajectory of the impact ball' center of gravity shown in Figure 14 which shows the increase in velocity while the impact ball drops from the swing angle of $45^{\circ}$ and the fast decrease in speed of the impact ball at the moment of impact with the composite fender, after approx. 0.6 seconds from starting time. 


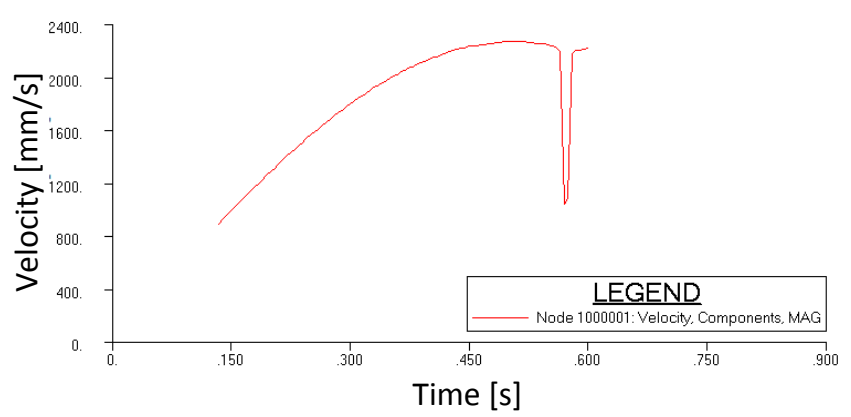

Figure 14. Simulation at $45^{\circ}$ swing angle using the composite fender [1]

Considering the high difference between the velocities given above, a deformation and stress analysis has been performed in order to better observe the behavior of the composite fender, with the results being acquired in the three key moments of the simulation: before, at and after the impact between ball and part, as shown in Figure 15 and Figure 16. The plots presented hereafter are only for the simulation at $45^{\circ}$ swing angle with the fender being made out of composite material [1]. It can be noticed that there is little to no deformation or stress state on the composite fender before the moment of impact due to the presence of only gravitational acceleration (Figure 15a and Figure 16a). At the moment of impact, there is an increase in both deformation and tension at the contact area between impact ball and composite fender (Figure 15b and Figure 16b), while after the impact, the analyzed part tends to return to its initial state (Figure 15c and Figure 16c).

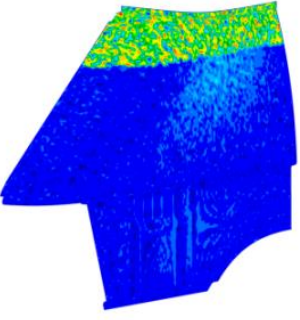

(a)

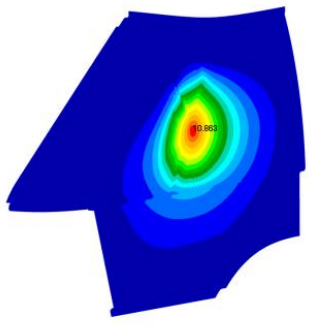

(b)

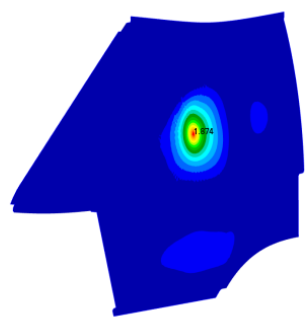

(c)

Figure 15. Deformation of the part: (a) before impact, (b) at impact and (c) after impact [1]

Mater. Plast., 57 (1), 2020, 175-190

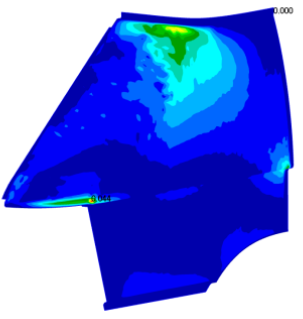

(a)

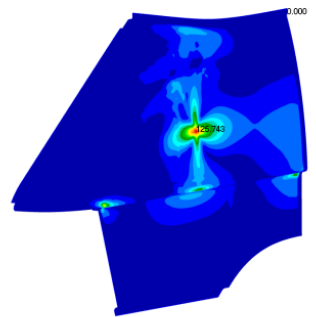

(b)
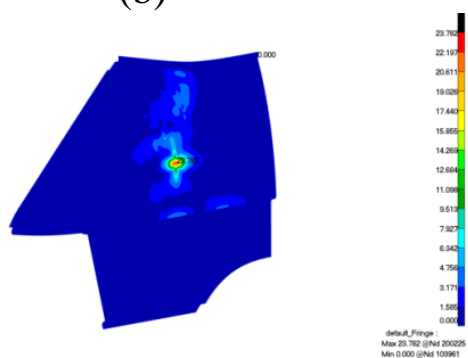

(c)
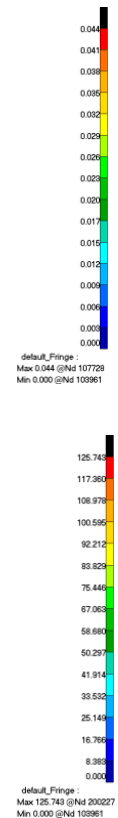

Figure 16. Von Mises stress of the part: (a) before impact, (b) at impact and (c) after impact [1] 
Another outcome worth mentioning is represented by the induced acceleration during the contact between impact ball and fender. Thus, for each swing angle, the following data is obtained from the simulation, [1]:

- Impact analysis with a starting swing angle of $45^{\circ}$ yields an acceleration of $18.2 \mathrm{~g}$;

- Impact assessment with an initial swing angle of $90^{\circ}$ gives an acceleration of $43.4 \mathrm{~g}$;

- Impact investigation at a maximum swing angle of $160^{\circ}$ leads to an acceleration of $54.3 \mathrm{~g}$.

This information will be corroborated with the data obtained from the laboratory testing in order to validate the FE simulation.

The results for the laboratory tests performed on the composite fender have been registered and compiled using the equipment shown in subchapter $\S 3.8$ and they are presented in Figure 17 to Figure 19.

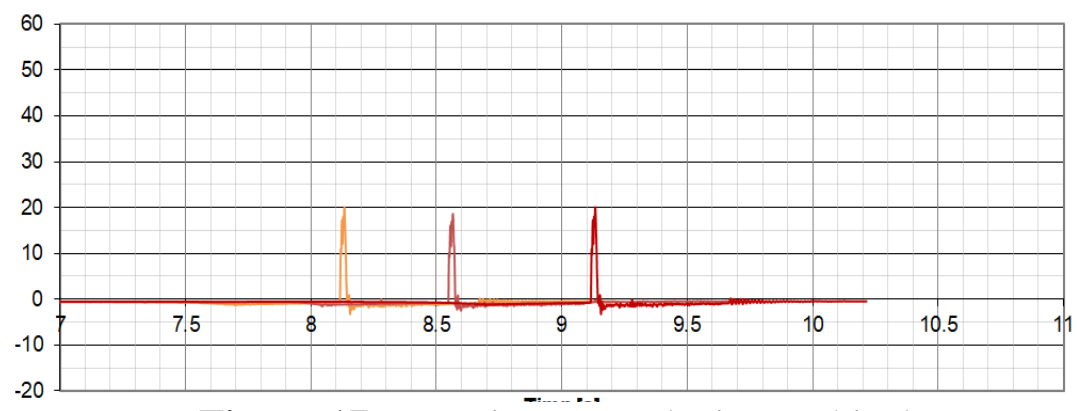

Figure 17. Experiment results in graphical format for $45^{\circ}$ swing angle [1]

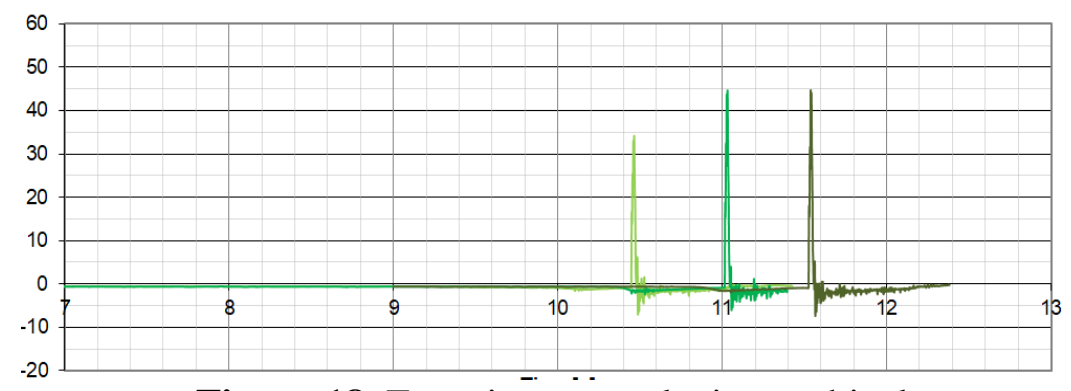

Figure 18. Experiment results in graphical format for $90^{\circ}$ swing angle [1]

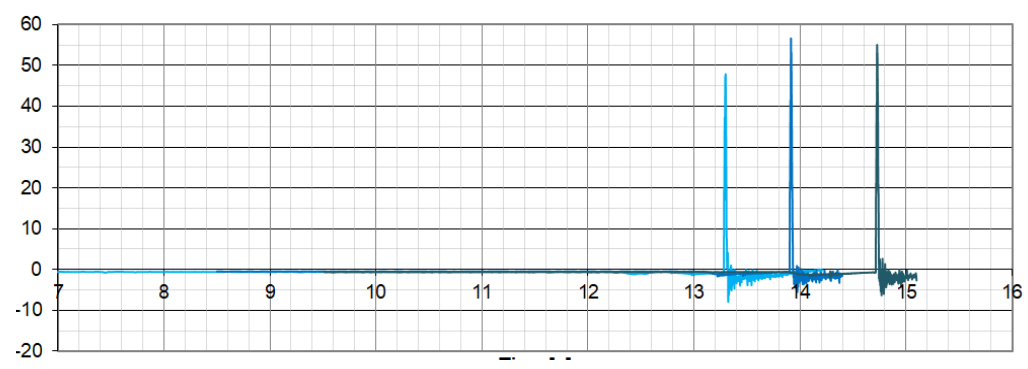

Figure 19. Experiment results in graphical format for $160^{\circ}$ swing angle [1]

By analyzing the obtained results, several conclusions can be drawn, [1]:

- Impact tests with a starting swing angle of $45^{\circ}$ yield a maximum accelerations reached of $20.1 \mathrm{~g}$, $18.6 \mathrm{~g}$ and $20.1 \mathrm{~g}$; considering the standard deviation of the utilized equipment is $+/-2 \mathrm{~g}$ and the maximum difference between registered accelerations is $1.5 \mathrm{~g}$, the tests can be considered compliant with one another (Figure 17).

- Impact trials with an initial swing angle of $90^{\circ}$ show a maximum accelerations registered of $34.2 \mathrm{~g}, 44.7 \mathrm{~g}$ and $44.6 \mathrm{~g}$; the difference between the first two tests is $10.5 \mathrm{~g}$, while the difference 
between the last two checks is $0.1 \mathrm{~g}$; the conclusion is that the first test at this swing angle is not consistent with the other two and its results should be neglected (Figure 18).

- Impact experiments at maximum swing angle of $160^{\circ}$ present maximum accelerations attained of $47.9 \mathrm{~g}, 56.5 \mathrm{~g}$ and $55.0 \mathrm{~g}$; the same conclusion as the impact test for a swing angle of $90^{\circ}$ can be drawn considering the difference between first two trials is $8.6 \mathrm{~g}$ and the difference between last two checks is $1.5 \mathrm{~g}$ (Figure 19).

The main cause for the experimental tests for which the results are considered non-compliant is the fact that the experiment is performed manually and the stand itself is not equipped with an engine which could raise the pendulum at a desired swing angle $\alpha$ and then release it. Note that the impact tests are carried out on different composite fenders for each of the swing angles mentioned beforehand.

The last step in the presentation and discussion of results is the comparison of outcomes between the induced acceleration obtained from the FE analysis and the acceleration measured from the experiments. An overview of the data from the FE simulations and experimental testing is shown in Table 6.

Table 6. Comparison between FE results and laboratory tests [1]

\begin{tabular}{|c|c|c|c|c|c|}
\hline Part & Swing Angle & $\begin{array}{c}\text { FE } \\
\text { Acceleration }\end{array}$ & $\begin{array}{c}\text { Test } \\
\text { Acceleration } \\
\text { Average } \\
\text { Value }\end{array}$ & $\begin{array}{c}\text { Test } \\
\text { Acceleration } \\
\text { Standard } \\
\text { Deviation }\end{array}$ & $\begin{array}{c}\text { Result's } \\
\text { Comparison }\end{array}$ \\
\hline \multirow{2}{*}{$\begin{array}{c}\text { Left fender of Renault } \\
\text { Espace I automobile }\end{array}$} & 45 degrees & $18.2 \mathrm{~g}$ & $19.6 \mathrm{~g}$ & 0.707 & Good match \\
\cline { 2 - 6 } & 90 degrees & $43.4 \mathrm{~g}$ & $44.7 \mathrm{~g}$ & 0.050 & Good match \\
\cline { 2 - 6 } & 160 degrees & $54.3 \mathrm{~g}$ & $55.8 \mathrm{~g}$ & 0.750 & Good match \\
\hline
\end{tabular}

As it can be seen, the comparison of results shows a good match and it can be concluded that the analyses performed in the virtual reality are validated by the assessments performed in laboratory [1].

\section{Conclusions}

This paper presented a procedure of validation for the finite element analysis of an automobile fender manufactured from Kevlar-Carbon composite material subjected to impact by means of experimental tests in order to have similar results and to demonstrate the advantages of the first named investigation for the production of parts used in the aerospace and / or automotive branch. For example, due to the high impact resistance, the Kevlar-Carbon composite panels could be used in the development of different parts of cars / motorcycles (i.e. left / right fenders / doors) or yachts (i.e. hulls, carcasses).

The information resulted from the finite element analysis is compared with the output data of the laboratory tests and a good match is concluded. Thus, this method of validation ensures that the FE simulation results are also covered by experiments facts which represent the actual behavior of the parts during an impact with another object. Furthermore, it establishes that the analyzed parts are manufactured according to the specifications of the industry and requirements of the clients, and that they have proper performance and structural reliability.

As a general conclusion, the composite materials chosen for the research presented in this paper have shown the desired and necessary properties from an impact point of view for the optimization of the analyzed part - left fender of a car. By means of FE model implementation, which is validated with laboratory tests, the investigation process comes to a close.

The research presented in this paper, alongside another study [21], have led the authors to the idea of developing an original software tool dedicated to the impact analysis of composite plates of simple and/or complex geometry. The tool itself would be validated by means of specialty literature data usage and future own experimental testing.

Acknowlegments: This article was presented at Polymer Processing in Engineering Conference - PPE 2019, 7- 9 October 2019, Galati - Romania. 


\section{References}

1. CROITORU, E. I., Research Regarding the Impact Testing of Thermoset Composite Panels Armed with Glass, Carbon and Kevlar-Carbon Fibers, $\mathrm{PhD}$ Thesis, Transilvania University of Braşov, Romania, 2019

2. ZIENKIEWICZ, O. C., TAYLOR, R. L., ZHU, J. Z., The Finite Element Method: Its Basis and Fundamentals, Butterworth-Heinemann, 2005

3. DAVIS, D., Finite Element Modeling of Ballistic Impact on a Glass Fiber Composite Armor, San Luis Obispo, USA, 2012

4. MURRAY, R. E., DOMAN, D. A., PEGG, M. J., Compos Struct, 121, 2014, p. 362-376

5. ZHANG, W., PAN, Z., GIDEON, R. K., GU, B., J Compos Mater, 49, 2014, p. 771-782

6. LIU, P. F., LIAO, B. B., JIA, L. Y., PENG, X. Q., Compos Struct, 149, 2016, p. 408-422

7. OSTRE, B., BOUVET, C., MINOT, C., ABOISSIERE, J, Compos Struct, 153, 2016, p. 478-489

8. REINOSO, J., BLAZQUES, A., Compos Struct, 139, 2016, p. 263-276

9. LIAO, B. B., LIU, P. F., Compos Struct, 159, 2017, p. 567-578

10. ROZYLO, P., DEBSKI, H., KUBIAK, T., Compos Struct, 181, 2017, p. 158-170

11. GINZBURG, D., Pinto, F., IERVOLINO, O., MEO, M., Damage tolerance of bio-inspired helicoidal composites under low velocity impact, Composite Structures, vol. 161, 2017, p. 187-203

12. IMRAN, M., KHAN, R., BADSHAH, S., IJST-T CIV ENG, 15, 2018

13. GONZALEZ, E. V., MAJMI, P., MARTIN-SANTOS, E., SOTO, A., CRUZ, P., de la ESCALERA, F. M., de AJA, J. S., , Int J Solids Struct, 144, 2018, p. 230-247

14. WANG, T., LI, Y., Adv Mech Eng, 7, 2015

15. KATKAR, A. D., BAGI, J. S., Int. J. Eng. Technol. Manag. Appl. Sci., 3, 2015, p. 272-279

16. MARZBANRAD, J., ALIJANPOUR, M., KIASAT, M. S., Thin-Walled Struct, 47, 2009, p. 902911

17. DAVOODI, M. M., SAPUAN, S. M., AHMAD, D., Ali, A., KHAlinA, A., JONOOBI, M., Mater Design, 31, 2010, p. 4927-4932

18. Renault Espace 4 Generations, Phase 1 Measures, available at: http://www.smcars.net/threads/ renault-espace-4-generations.24512/, 2007, accessed 06.06.2017

19. Hexcel Corporation, Product Data Sheet for HexPly® M49 $120^{\circ} \mathrm{C}$ curing epoxy matrix, $3 \mathrm{~K}$ High Strength Carbon, available at: https://www.hexcel.com/user_area/content_media/raw/HexPly _M49_eu_DataSheet.pdf, accessed 22.07.2017

20. Hexcel Corporation, Product Data Sheet for HexPly® F155 Resin Systems for Advanced Composites, Epoxy Resin with Kevlar Fabric K285, available at: https://www.hexcel.com/user_area/ content_media/raw/HexPly_F155_us_DataSheet.pdf, accessed 22.07.2017

21. CROITORU, E. I., OANCEA, G., CONSTANTIN, N., Rev Rom Mater, 54, 2017, p. 700-707

Received Month Date, 2019

Manuscript received: 31.12.2019 